\title{
IMAGINARIOS DE MODERNIDAD EN LA FOTOGRAFÍA CHAQUEÑA. ARGENTINA 1900-1978
}

\author{
MODERNITY IMAGINARIES IN CHACO PROVINCE \\ PHOTOGRAPHY. ARGENTINA 1900-1978
}

\section{ALEJANDRA REYERO ${ }^{1}$ \\ LUCIANA SUDAR KLAPPENBACH ${ }^{2}$}

\section{RESUMEN}

El objetivo de este trabajo es abordar la incidencia de las imágenes fotográficas de tres autores (Juan Bautista Simoni, Pablo Boschetti y Pedro Luis Raota) en la conformación de imaginarios de modernidad en la provincia de Chaco, Argentina, entre 1900 y 1978. Analizar por un lado, la función y significación de estas imágenes, entendidas como expresiones culturales del proceso de modernización argentina y, por otro, su anclaje en la memoria regional y nacional. Esta articulación entre fotografía, imaginario y memoria nos permite identificar algunos de los conflictos, utopías y transformaciones sociales, materiales y culturales del Chaco en el siglo XX. Para ello consideramos como criterio historiográfico la complementariedad de la relación imagen fotográfica / cultura histórica regional, perspectiva sobre la que se orienta el modelo metodológico propuesto y según el cual se indaga en la significación de las producciones fotográficas mencionadas.

Palabras clave: Fotografía, imaginario, modernidad, Chaco-Argentina.

\section{ABSTRACT}

The study undertakes the incidence that photographic images of three authors - Juan Bautista Simoni, Pablo Boschetti and Pedro Luis Raota - had in the shaping of modernity imaginaries in Chaco Province, Argentina between 1900 and 1978. It analyses on the one hand, the function and meaning of these images as cultural expressions of the

${ }^{1,2}$ Núcleo de Estudios y Documentación de la Imagen (NEDIM)-IIGHI, Facultad de Humanidades Universidad Nacional del Nordeste (UNNE), Chaco-Corrientes, Argentina. E-mail: alereyero@hotmail.com, luciana.sudar@gigared.com.ar 
modernization process in Argentina, and its regional and national memory anchorage on the other. The link between photography, imaginary, and memory allows us to identify some of the tensions, conflicts, utopias and social transformations, both material and cultural, of Chaco Province in the $20^{\text {th }}$ Century. For that we take as historiographic criteria the complementarities in the relationship between photographic images / regional cultural history, as a perspective guiding the methodological model we propose by which the meaning of the mentioned photographic productions is investigated.

Keywords: Photography, imaginary, modernity, Chaco-Argentina.

Recibido: 27.09.10. Aceptado: 12.01.11.

\section{INTRODUCCIÓN}

I ENTENDEMOS que toda fotografía es una representación culturalmente codificada, la información que ésta transmite -referida a un tema o asunto particular- es inseparable de la elección que el fotógrafo realiza de acuerdo a sus propias motivaciones y a las coordenadas espacio-temporales que delimitan el fragmento de la realidad capturada.

En tal sentido, considerar a la fotografía como una fuente a través de la cual pueda obtenerse información del pasado, supone no sólo situarla en un contexto histórico específico, sino también contemplar la acción y decisión de su autor. La sensibilidad, el bagaje cultural, los intereses estéticos, ideológicos que actúan como filtro de quien obtura la cámara y que transforman lo real en representación.

De esta forma, en tanto producto de una intención subjetiva, la imagen adquiere determinada significación simbólica. Significación en función de la cual se halla intrincada con la capacidad de expresar imaginarios sociales y de contribuir a la construcción visual de una memoria histórica.

La relación entre la imagen, su uso, significación y efecto en la conciencia colectiva, conforma determinado imaginario. Éste alude -desde la perspectiva del sujeto- a una idea o conciencia interiorizada en el intelecto respecto a una cierta realidad. La idea que el individuo se forma sobre algo y que en el caso de la fotografía encuentra su referente en la imagen que ésta muestra.

Si bien el término imaginario se encuentra asociado a la significación subjetiva y mental, también se refiere al conjunto de imágenes físico-materiales unidas por un vínculo temático susceptible de ser analizado como corpus documental con una unidad semántica precisa (Rojas Mix, 2006).

Los imaginarios visuales del Chaco se han configurado a partir de nume- 
rosos y variados registros fotográficos que han circulado tanto en el medio regional como nacional e internacional. Los más conocidos en referencia a este territorio estuvieron vinculados a la imagen del indígena, no obstante existió una producción fotográfica local, que alejándose de la mirada etnográfica pretendió difundir una imagen del Chaco centrada en la figura del inmigrante europeo y en los escenarios cotidianos que dieran cuenta de la modernidad y el progreso. Pioneros, aficionados y artistas consolidados de la fotografía chaqueña, autores como Juan Bautista Simoni, Pablo Boschetti y Pedro Luis Raota aportaron, desde ángulos, intereses y contextos diversos, su visión de la realidad chaqueña. Ubicadas entre el testimonio, la cotidianeidad, el arte y la búsqueda de la identidad regional, estas imágenes nos remiten a momentos de la historia chaqueña caracterizada por importantes cambios socioculturales.

El objetivo de este trabajo es abordar la incidencia de las imágenes fotográficas de estos tres autores (Simoni, Boschetti, Raota) en la conformación de imaginarios de modernidad del Chaco. Analizar, por un lado, la función y significación de estos registros visuales como expresiones culturales del proceso de modernización argentina y, por otro, su anclaje en la memoria chaqueña. Esta articulación entre fotografía, imaginario y memoria nos permitirá identificar algunos de los conflictos, utopías y transformaciones sociales, materiales y culturales del Chaco en el siglo XX.

Para ello consideramos como criterio historiográfico la complementariedad de la relación imagen fotográfica / cultura histórica regional (Priamo, 2000 , p. 11) perspectiva sobre la que se orienta el modelo metodológico propuesto y según el cual se indaga en la significación de las producciones fotográficas mencionadas.

Contemplando por un lado, el análisis histórico contextual intentamos determinar las dimensiones culturales y espacio-temporales de los registros visuales y por otro, a través del análisis intrínseco de las imágenes, identificar sus dimensiones temáticas, estéticas y discursivas, para lo cual seguimos los lineamientos conceptuales-metodológicos de Rojas Mix (2006, pp. 234-248). Según esta perspectiva, la imagen es abordada desde el ángulo de la significación, esto es, en función de su capacidad de producir sentido y expresar ideas en determinados contextos epocales. Dicho esquema de análisis -basado en los tradicionales aportes de la iconografía de Erwin Panofsky- establece un abordaje de acceso a la imagen a través de un recorrido por diferentes fases. Según nuestros intereses analíticos, en este trabajo haremos principal hincapié en cuatro de estas fases: la fase contextual-histórica, la descriptiva, la interpretativa y finalmente la comunicativa. 
Los ejes sobre los cuales abordaremos las colecciones fotográficas de Simoni, Boschetti y Raota, giran en torno de tres referentes visuales identificados en cada una de las producciones: 1) el hombre chaqueño, 2) su espacio y entorno (natural y material) y 3 ) su producción (económica y cultural). Los tres referentes se enmarcan en el contexto de modernidad de la Argentina republicana, consolidada a partir de su integración al mercado mundial de comercio y producción.

Dadas las múltiples dimensiones que comprende la definición de modernidad, el análisis visual propuesto tendrá como eje a la modernidad entendida paralelamente como época o, en palabras de Berman, "experiencia histórica", como proceso socioeconómico -caracterizado por importantes fluctuaciones y transformaciones- y finalmente, también, como discurso o conjunto de valores, visiones y representaciones acerca de la experiencia social de este proceso. Valores, visiones y representaciones materializadas en manifestaciones culturales concretas: en nuestro caso, las imágenes fotográficas de Simoni, Boschetti y Raota.

\section{GEOGRAFÍAS DE LA INTIMIDAD. EL ESPACIO PRIVADO COMO SIGNO DE PROSPERIDAD}

La labor fotográfica en el Chaco se inicia de la mano de Juan Bautista Simoni, quien como actividad complementaria a sus oficios de herrero y carpintero se dedicó como aficionado a registrar fotográficamente la vida de Resistencia y sus alrededores en los primeros años de 1900. Hijo de inmigrantes italianos, llegó a esta región junto a sus padres en 1879, desde la oriunda ciudad de Borgo (Tirol, entonces bajo dominio austríaco).

Enfocó especialmente su lente en los rostros de los pobladores inmigrantes de la región, en su mayoría italianos, quienes con su llegada oficializaron la fundación de esta ciudad en 1878, efectivizando así el proyecto colonizador de la Argentina decimonónica.

Algunas fotografías de la entonces colonia de Resistencia y otras aledañas en sus primeros años, que circulan hoy en centros de documentación, museos y archivos, y que han sido publicadas en medios de prensa, pueden atribuirle su autoría, ya que se desconoce la labor de otro fotógrafo en la zona a fines del siglo XIX y primeros años del siglo XX. Para aquel entonces la actividad fotográfica era considerada como un oficio de artesano y no como una tarea de artista o intelectual. No era un medio económico de vida plenamente aceptado sino simplemente un oficio alternativo. No obstante, 
en la vecina ciudad de Corrientes existieron numerosos estudios fotográficos, a los que acudían las familias inmigrantes recientemente asentadas en la colonia Resistencia.

Este primer conjunto iconográfico propuesto por Simoni, nos ofrece un interesante y variado panorama de la vida social de los primeros pobladores inmigrantes de Resistencia. De su valioso legado fotográfico tomamos para esta investigación un conjunto de ochenta y seis placas de vidrio que reflejan aspectos sociales de la incipiente población de Resistencia.

Retratos individuales y grupales, escenas cotidianas, eventos comunitarios (religiosos y educativos), paisajes y ambientes familiares son los principales focos de su mirada fotográfica. El copioso y variado conjunto de estas imágenes nos permite inferir que en muchas oportunidades éstas debieron responder a una demanda particular, ya que la fotografía familiar y social como género iconográfico, suponía en aquel entonces una auténtica ceremonia en la que la mayoría de los miembros se reunía a celebrar y afianzar sus vínculos.

Sumado al uso de la foto familiar como medio de autoconocimiento y perpetuación, la imagen fotográfica formaba parte de la correspondencia enviada a los familiares que se hallaban en el "Viejo Continente". Ello permitía no sólo una confirmación de vida, sino también una "muestra" de las formas y estilos de vida alcanzados, contribuyendo así al afianzamiento del núcleo familiar entre quienes habían emigrado y quienes se hallaban en el lugar de origen.

En el contexto en que Simoni obtiene sus imágenes, la toma fotográfica representa quizás la única posibilidad de concretar el anhelo de perennidad y afirmación identitaria de los inmigrantes europeos. En particular el hecho de retratarse constituyó para algunos de ellos un logro inesperado, ya que hasta el advenimiento de la fotografía (época que coincide con el comienzo de las corrientes migratorias hacia América) el género pictórico del retrato se había establecido como privilegio de una pequeña elite. Sin embargo en estas nuevas tierras fueron algunos de estos inmigrantes quienes se convirtieron en el sector privilegiado con acceso a este nuevo medio de registro.

Al no contar con un estudio fotográfico, muchas de las tomas logradas por Simoni implican una puesta en escena. Tanto la incorporación de elementos precisos (floreros, instrumentos musicales, abanicos, libros, sillas, mesas, almohadones) como la disposición de lo sujetos y el encuadre elegido, sugieren un intento por parte del fotógrafo de ambientar la escena para sugerir un ámbito de estudio (Imagen 1). En particular el hecho de colgar en casi todas las tomas una sábana o paño a modo de telón de fondo 


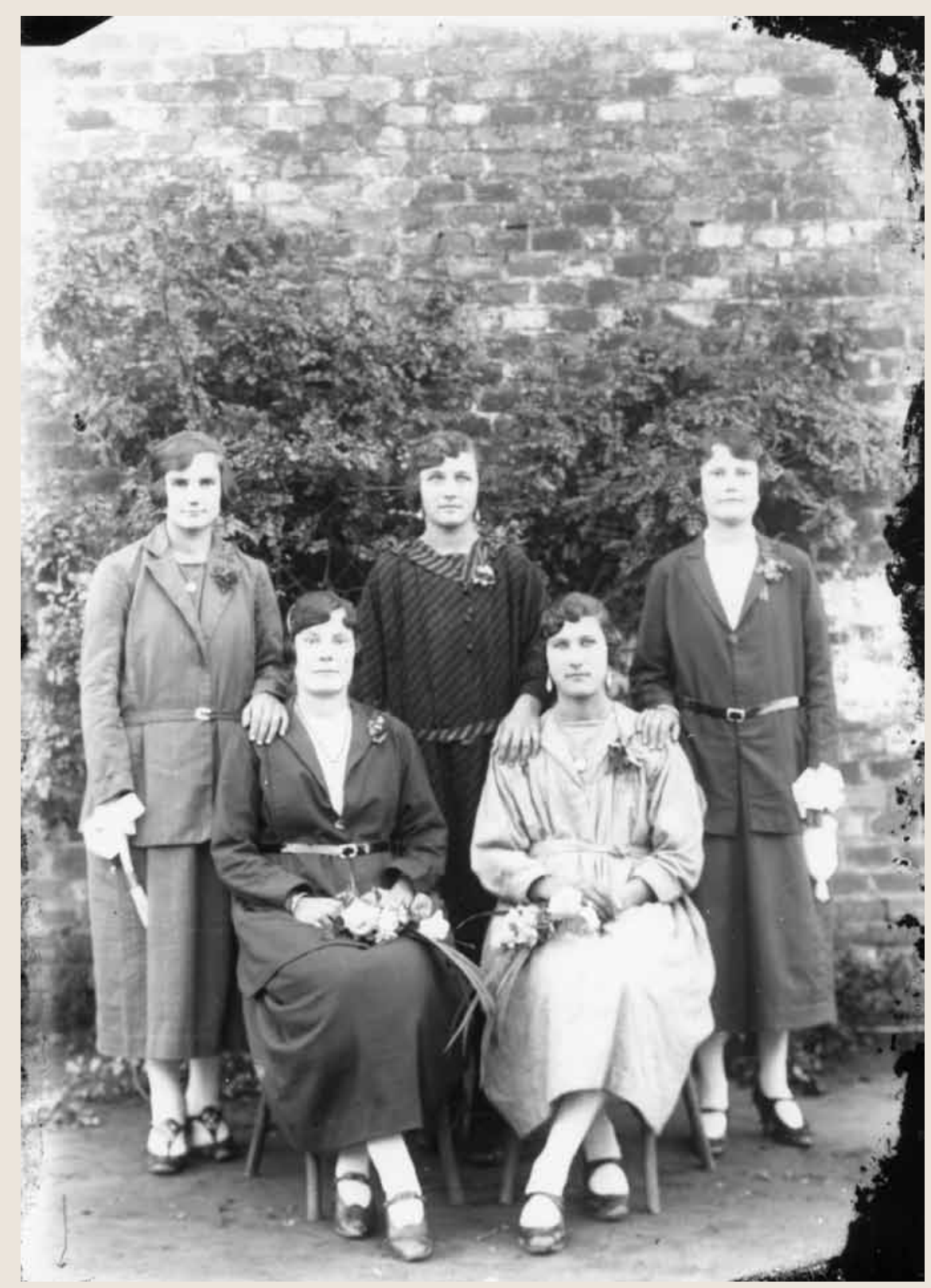

Imagen 1. Juan Bautista Simoni. Ca.1905. Col. NEDIM. 


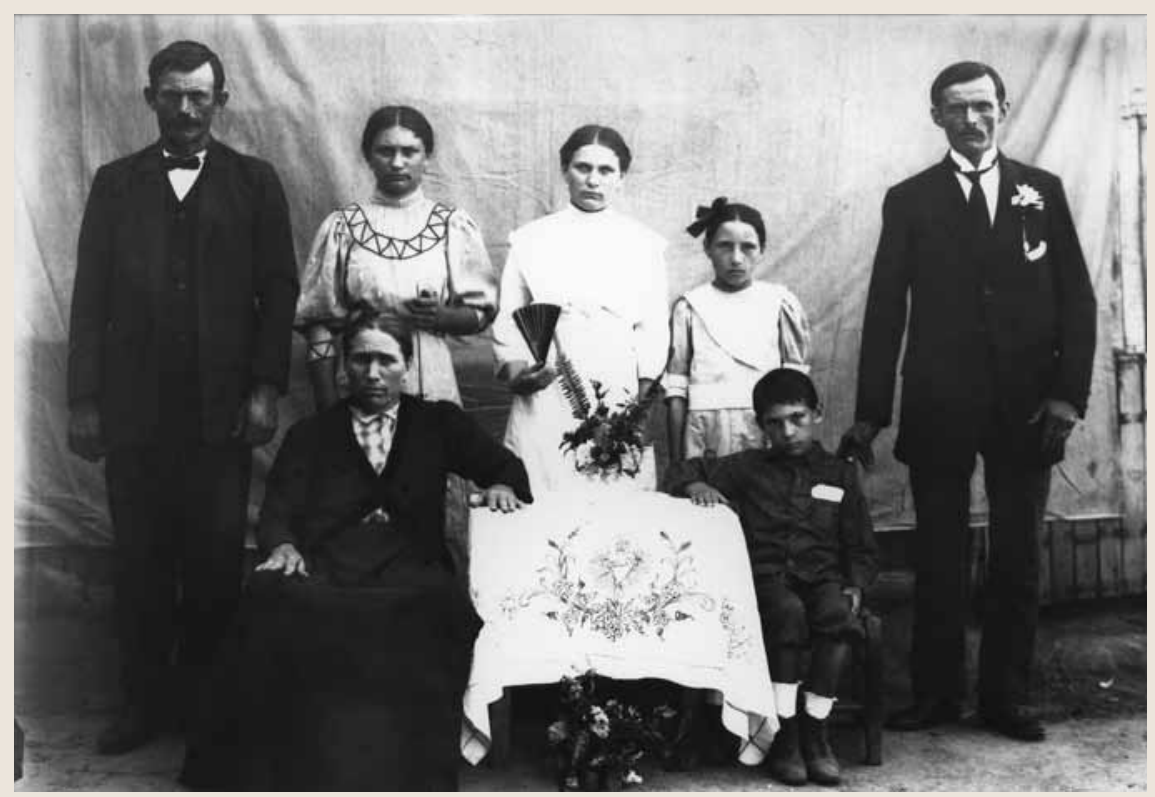

Imagen 2. Juan Bautista Simoni. Ca.1905. Col. NEDIM.

para resaltar las figuras y situaciones representadas. Sumado a ello, también observamos una clara intención de componer la escena según las clásicas convenciones del género del retrato del siglo XIX: las "figuras principales" a destacar (en este caso padres o abuelos) se ubican de pie o sentados en el centro de la imagen. A éstos los rodean los "personajes secundarios" (hijos, nietos o demás familiares). El ángulo elegido destaca siempre un eje central ocupado no sólo por los protagonistas del encuadre, sino también por otros objetos (en particular, mesas con floreros) a cuyos lados se ubican los demás elementos retratados, logrando un perfecto orden de simetría visual (Imagen 2).

La mayoría de las escenas se componen en los ambientes exteriores de las mismas viviendas de los fotografiados (galerías, jardines, quintas, chacras). Ello estaría asegurando un registro más fiel mediante un foco de luz natural, ya que en la época de 1900 la colonia no contaba con un sistema de alumbrado artificial que garantizara una óptima realización de la toma. El paisaje abierto, por otro lado, refleja también la realidad agraria y rural de los territorios recién explotados, reivindicando de este modo el aporte productivo del inmigrante colono en la "construcción de su nueva patria" (Imagen 3). 


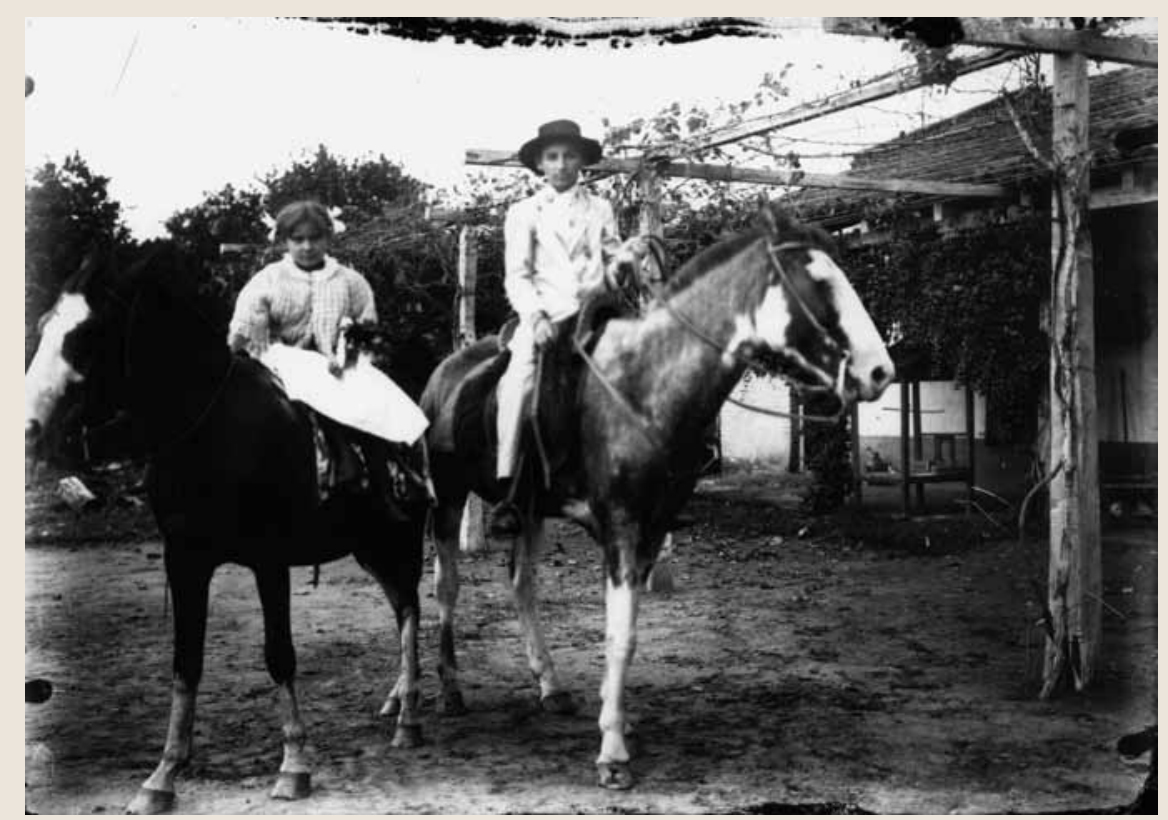

Imagen 3. Juan Bautista Simoni. Ca.1905. Col. NEDIM.

El factor humano es un elemento clave en este conjunto iconográfico. La mayoría de los personajes retratados subrayan una falta de espontaneidad en los rostros, gestos, poses y actitudes, que se ve reemplazada por una expresión de quietud y recato, cercana al sobrecogimiento. Este rasgo estaría respondiendo no sólo a una convención estética sino también a los requerimientos técnicos de exposición que la precaria tecnología fotográfica del momento demandaba. Por otro lado, la ausencia de expresiones afables y naturales de los retratados los desplaza de las características individuales hacia tipos sociales capaces de demostrar y confirmar una identidad social y cultural determinada: la del colono inmigrante, trabajador, emprendedor y comprometido con la tierra que le diera abrigo. Ello aparece demostrado por la presencia de trajes y vestimenta festiva que acompaña el gesto solemne y ostentador de la mayoría de los personajes retratados a quienes los contienen -en la casi totalidad de las imágenes- los cauces de la tierra labrada.

Las imágenes de Simoni son entonces fieles testimonios de la cultura de la inmigración. Cultura regional a través de la cual se expresaba la aventura colonizadora, como parte de la incipiente modernidad regida por el ideal 
del trabajo y el progreso. Dicho ideal conforma el sustrato ideológico e identitario de estos primeros registros fotográficos de la realidad chaqueña.

\section{LA CIUDAD COMO IDEAL DE PROGRESO: HACIA UNA NUEVA IMAGEN DEL ESPACIO CHAQUEÑO}

Décadas más tarde contamos con la presencia de otro de los grandes fotógrafos que dejaron su impronta en el patrimonio visual chaqueño. Se trata de Pablo Boschetti. Nacido en Asunción, capital del vecino país de Paraguay el 20 de julio de 1905 y radicado en Resistencia en 1921, se introduce en el mundo de la fotografía colaborando con la labor de Vicente Vía. Fue con él con quien aprendió la técnica fotográfica, por lo que muchas de las primeras imágenes de Resistencia que pertenecen al sello de Vía pudieron haber sido tomadas tanto por éste como por el mismo Boschetti.

En 1929, Boschetti logra instalar su propio estudio fotográfico conocido como "Foto Boschetti". A partir de allí, rápidamente sus primeras imágenes comienzan a verse en numerosas ediciones gráficas de la época. Entre ellas una de las primeras revistas ilustradas del Chaco, Estampa Chaqueña, y el diario más representativo de aquel entonces: El Territorio. Pero su actividad no sólo se concentró en cubrir la gráfica periodística local, sino que abarcó también la producción de fotografías destinadas a su publicación en otros medios de difusión. Entre ellos la Guía Comercial del Chaco de 1936 y el Álbum Gráfico Descriptivo de 1935. El desempeño de Boschetti como fotógrafo de la prensa local y de demandas públicas y privadas fue continuo hasta 1970 , momento en que vende su estudio a una cooperativa conformada por sus empleados y abandona definitivamente su labor fotográfica.

En contraposición a la realidad rural representada en la fotografía de Simoni, casi 30 años más tarde, Pablo Boschetti nos enfrenta con el cambiante paisaje urbano de Resistencia. Con tomas que captan en su contenido visual elementos de la escena urbana: calles, vegetación, conjuntos edilicios, espacios públicos, infraestructura urbana, transportes, etc., accedemos a una nueva imagen de la realidad chaqueña. El corpus visual de Boschetti que abordamos en este trabajo integra las vistas urbanas y edilicias de Resistencia y sus alrededores. La casi totalidad de estas imágenes alude directa o indirectamente al proceso de transformación atravesado por el paisaje de la metrópoli. A través de ellas nos aproximamos imaginariamente al contexto urbano-arquitectónico de Resistencia de la década del '30.

Boschetti plasma en el papel fotográfico distintas maneras de mirar y 
comprender la ciudad: las vistas aéreas, los recorridos urbanos y las tomas puntuales de edificios conforman este repertorio.

Las tomas aéreas representan imágenes poco convencionales para la época. La mayoría fue realizada por sucesivas demandas político-administrativas de los gobiernos locales (municipal y provincial), que encontraron en la fotografía aérea un medio eficaz para reconocer el territorio. A través de una lectura bidimensional, las vistas aéreas permitían una comprensión integral del espacio sobre el que se desarrollaba, extendía y densificaba Resistencia, convirtiéndose en legítimos instrumentos técnicos para la planificación territorial (Imagen 4).

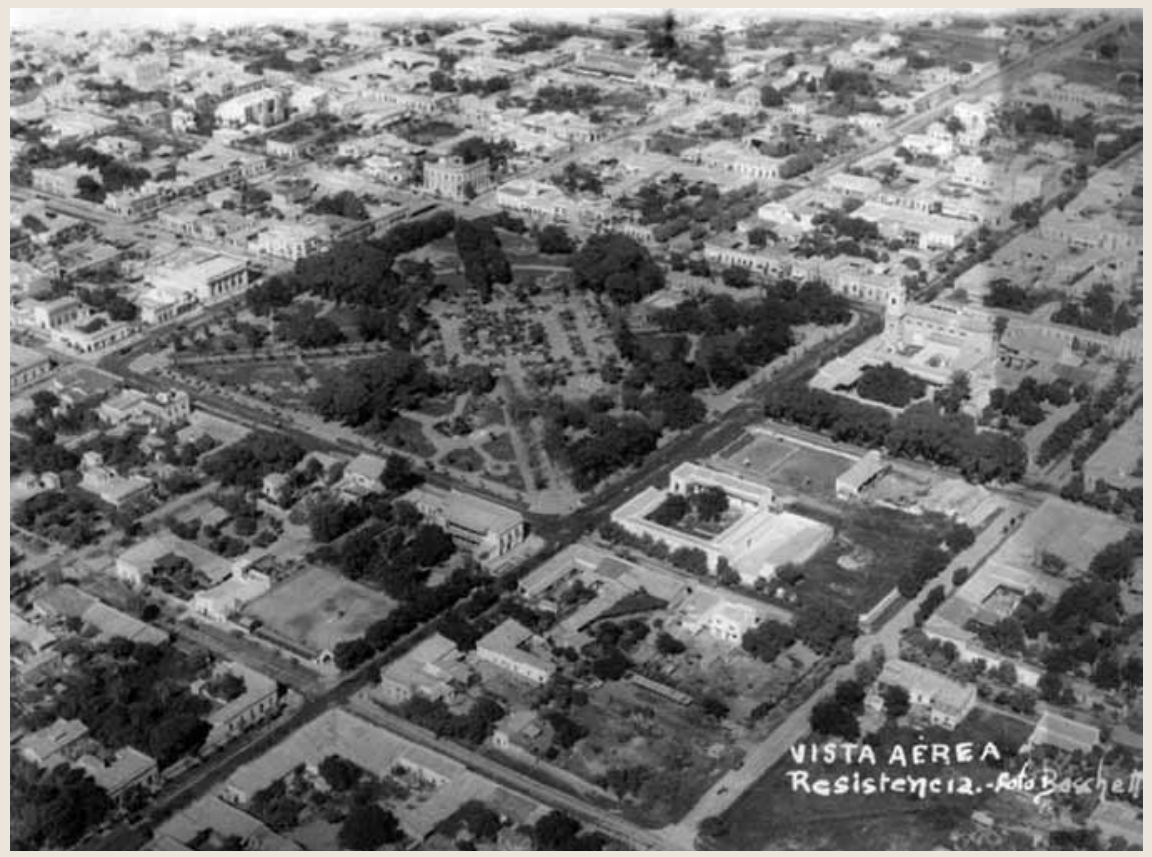

Imagen 4. Pablo Boschetti. Ca.1935. Col. NEDIM.

Desde esta "mirada cenital" irrumpía la ciudad regular, la cuadrícula originaria, perfecta, como primera manifestación de la mano civilizatoria sobre los territorios del Chaco. Pablo Boschetti captaba así desde un piper bi plano, una nueva escala de lo urbano, dando cuenta de la racionalidad de su trazado y haciendo que sus imágenes lleguen a asemejarse a un dibujo 
planimétrico capaz de ofrecer una visión de la ciudad y su entorno difícilmente imaginable desde la usual mirada peatonal.

La plaza central y sus alrededores, las áreas portuarias de Barranqueras, las lagunas que surcaban los suelos sobre las que debía erigirse la ciudad, los establecimientos fabriles, el complejo hospitalario regional, constituyen así las áreas de referencia fijadas en estas tomas.

Evidenciando el preciso y sistemático trazado territorial, las tomas de Boschetti revelan la geografía urbana en constante transformación. Esta racional manera de concebir el espacio se corresponde con la visión positivista de la época según la cual lo urbano debía resultar una manifestación de orden y progreso.

Otro de los enfoques lo componen las vistas urbanas concentradas en los sectores más beneficiados por las gestiones institucionales del período. Muchos de ellos conformaban los puntos clave de referencia para el recorrido habitual de los ciudadanos. Se revelan así las pocas calles pavimentadas acompañadas de los servicios de infraestructuras adecuadas, que hasta el momento se habían efectivizado en el centro de la ciudad (Imagen 5). En

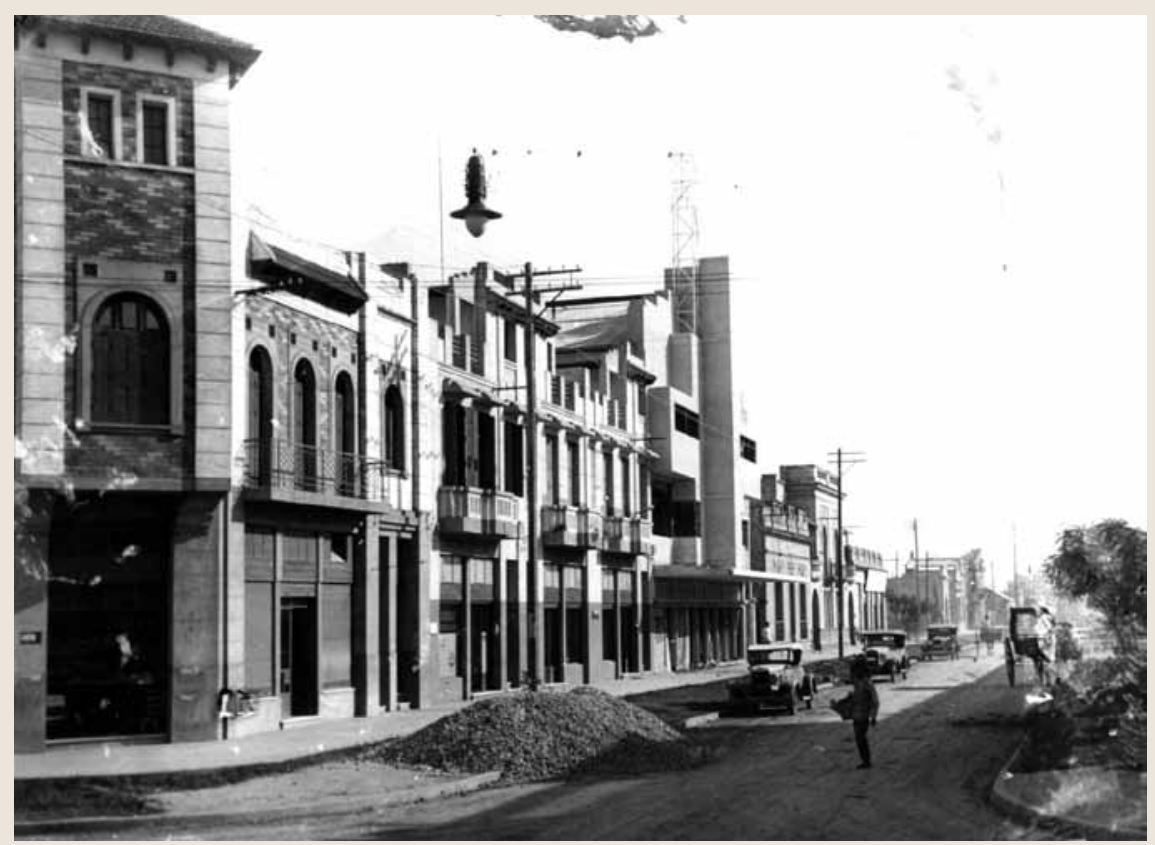

Imagen 5. Pablo Boschetti. Ca.1935. Col. NEDIM. 
estos sectores consolidados se emplazaba la mayoría de los edificios existentes, a la vez que algunos desaparecían parcialmente. Estos escenarios eran los encargados de conferir a la ciudad la imagen más urbanizada.

En este sentido es interesante remarcar la minuciosa selección que realiza Boschetti movido por una clara intención de sobrevaluar la calidad ambiental y estética de Resistencia en pos de un ideal de modernidad. Relegando gran parte de la realidad urbana de Resistencia sumida a múltiples conflictos de habitabilidad, salubridad y ausencia de servicios públicos.

Se observan también algunas tomas de edificios que corresponden a registros puntuales de las obras más emblemáticas de la ciudad, sea por la función que acogían (estaciones de ferrocarril, hospital regional, escuelas, etc.) como por la calidad arquitectónica y estilística que ostentaban.

Dentro del repertorio arquitectónico privado, Boschetti registró los edificios residenciales que correspondieron a personajes de la elite resistenciana. Estos edificios se erigían en la ciudad como paradigmas de una arquitectura "distinguida e individual" en contraposición a aquella italianizante popular que hasta el momento había definido un perfil homogéneo de la ciudad.

Por su parte la arquitectura oficial también encontró un lugar en la lente de Boschetti y luego en las páginas de prensa de la gráfica local. Las dos estaciones de ferrocarril, el Hospital Regional, la sede del Banco Nación y el de Italia y Río de la Plata, la Cárcel construida en los primeros años de 1930, aparecen impresas desde diferentes ángulos en muchas de sus imágenes (Imagen 6). Así también los espacios que albergaban funciones culturales y recreativas como ser el Teatro Argentino, Radio Chaco, el Cinematógrafo S.E.P, entre otros.

No escapan a la mirada de Boschetti aquellas vistas referidas a la producción, comercialización y transporte. De tal forma, algunas industrias locales, el mercado municipal y principalmente los distintos sectores y componentes del Puerto de Barranqueras (muelles, galpones, camiones, grúas, etc.) forman parte de su variado registro.

Todos ellos se configuran así en legítimos signos de modernidad plasmados en una composición visual en la que se advierte explícitamente la intención de "mantener el orden convencional de lo visible, equilibrar la escena buscando simetría, ubicar lo destacable en el centro, graduar la relación entre fondo y figura y entre los distintos planos de composición" (Marta Miras, 2003, p. 59). 


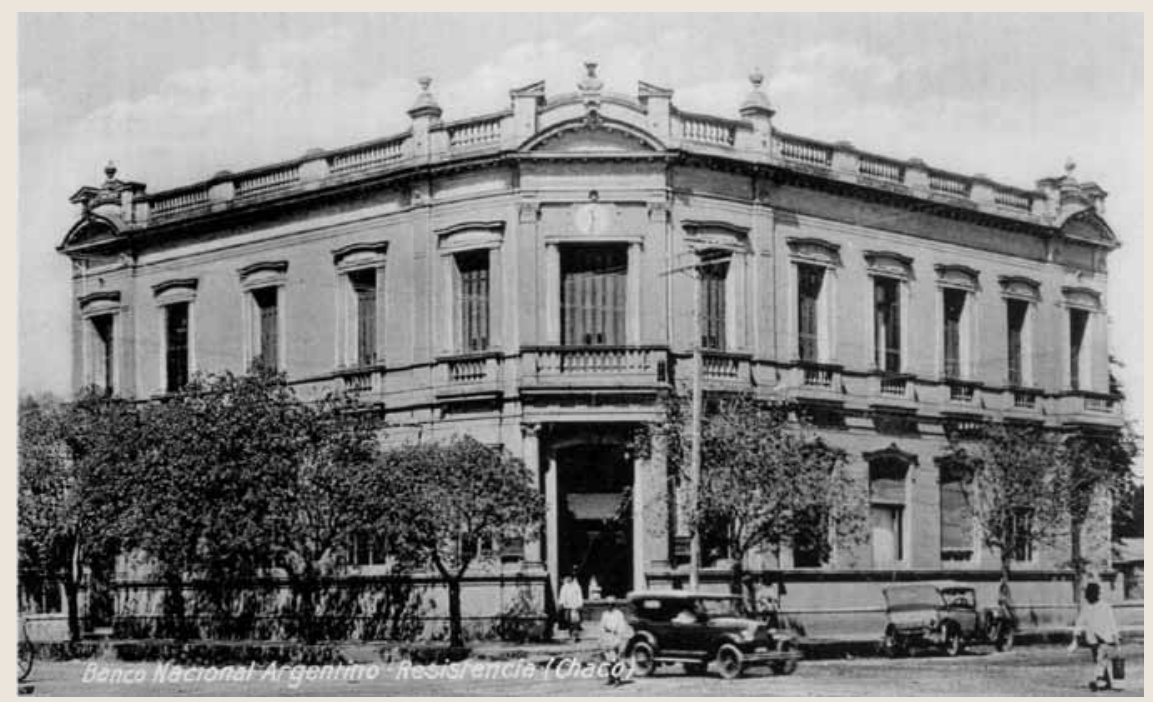

Imagen 6. Pablo Boschetti. Ca.1935. Col. NEDIM.

\section{DE LA COTIDIANEIDAD A LA "NACIONALIDAD". LA FOTOGRAFÍA COMO VEHÍCULO DE MODERNIDAD}

La producción fotográfica chaqueña del siglo XX con la que culmina el recorte aquí propuesto, corresponde a una de la figuras de mayor reconocimiento nacional e internacional: Pedro Luis Raota.

Nacido en el interior de la provincia de Chaco, se muda siendo muy joven a la ciudad de Santa Fe, donde adquiere las primeras nociones de fotografía y donde inicia su carrera haciendo fotos carnet. Se traslada luego a Villaguay, Entre Ríos, ciudad en la que abre un estudio fotográfico desarrollando una intensa labor artística que lo lleva a presentar sus fotografías en diferentes concursos y exposiciones en salones nacionales e internacionales. Obtiene así premios en distintos países y desde 1981 dirige en Buenos Aires el Instituto Superior de Arte Fotográfico hasta 1986, año en el que fallece.

Ubicadas en este mismo ideal de progreso que las otras dos colecciones, las imágenes de Raota expresan en su totalidad los hábitos, horizontes, y proyecciones del "hombre chaqueño" en la década de 1970.

A dicho autor se lo ubica en la historia de la fotografía argentina entre los fotógrafos referentes del Fotoclubismo. Asimismo su accionar y produc- 
ción fotográfica estuvo relacionada con la etapa correspondiente a la dictadura militar, siendo uno de los autores de las imágenes que se distribuían hacia el exterior por medio de la Cancillería, particularmente por el Centro Piloto de París, como medio de difusión de una imagen oficial asociada al bienestar y progreso, contrarrestando la aberrante realidad político-social en la que se encontraba el país. De esta manera la fotografía, y en este caso la correspondiente a Raota, jugó un rol sobresaliente en la formación de una imagen nacional para el país y el mundo, dando cuenta de su poder cultural para transformarse en varias oportunidades, en un medio de "propaganda ideológica" (Fernández, 2006).

Como toda colección fotográfica, la que consideramos en este trabajo se halla unificada no sólo en la correspondencia al mismo autor, sino también y en especial a una interesante unidad semántica centrada principalmente en la figura del colono inmigrante (para este entonces "el gringo") residente en Resistencia y otras localidades del interior chaqueño (Sáenz Peña, Quitilipi, Las Breñas, Castelli, etc.) (Imagen 7). Producto de un encargo del entonces Banco del Chaco, este conjunto de imágenes hace suyo el lema ideológico que lo definía: "Chaco puede".

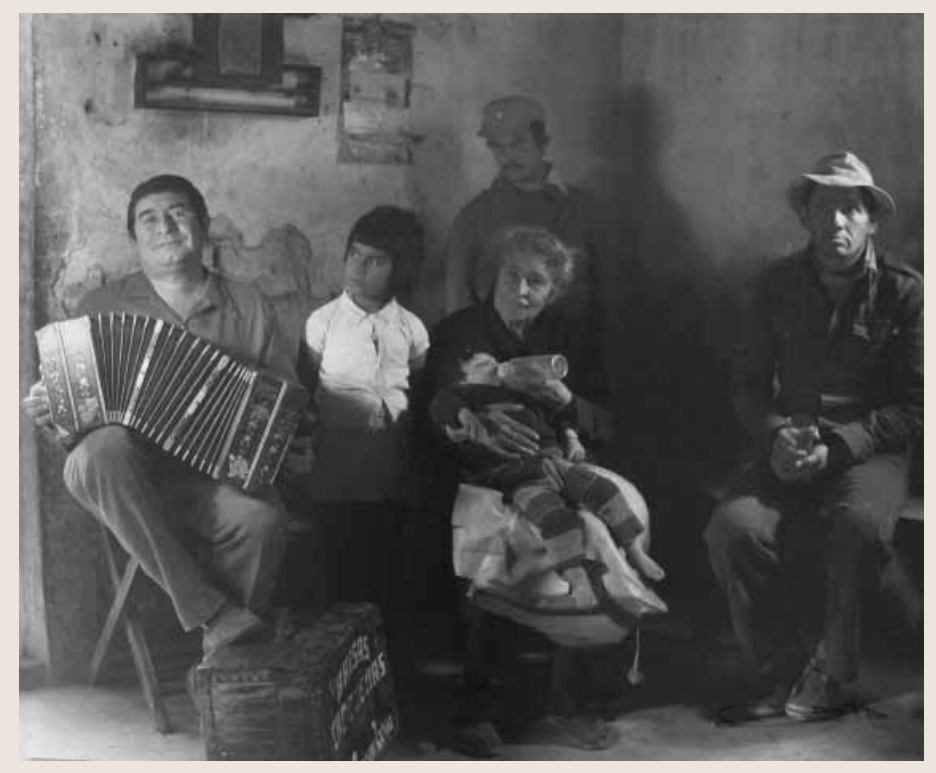

Imagen 7. Pedro Luis Raota La verdulera. Ca. 1978. Col. Banco del Chaco. Museo Provincial de Bellas Artes René Brusau. 
Con títulos en cierto modo elementales que expresan explícitamente el interés político perseguido, todas las imágenes pretenden contribuir con la concreción de aquel ideal, sumarse de algún modo al proyecto civilizatorio combatiendo el Chaco "desierto" y transformándolo en la "tierra del porvenir". Expresiones como Algodón, Las vías del progreso, Así se construyó la patria, Quemando rastrojos, Gringa chaqueña, Chaco hoy, Mecanizándose, Enseñando a amar, El nuevo Chaco, Sol y Quebracho, Cielo y Carbón, Arreando mi tropa, El pan nuestro de cada día, Campaña del oeste, Preparando la tierra, complementan la información visual unificada por una temática precisa: aquella focalizada principalmente en un ideal de colonización y prosperidad.

En lo que a cuestiones operativas se refiere, sabemos que Raota elegía premeditadamente -siempre que las circunstancias se lo permitieran- el foco de su registro. Un paisaje natural era a veces el disparador de una escena que intuía interiormente y que tras obtener los recursos necesarios (sujetos, objetos, ubicación de la cámara) inmediatamente montaba para la realización de la toma deseada. En otras ocasiones, en cambio, la imagen lograda pareciera transferir cierta atmósfera intimista y natural de algunos espacios privados como la propia casa del gringo en la que se amasaba el pan, se tomaba mate o se enseñaba a los niños a leer.

Ello no sólo nos remite a las percepciones, intereses y "motivos" propios del contexto de producción de estas imágenes, sino también enfatiza el hecho de que "la elección de un aspecto determinado (...) la preocupación por la organización visual de los detalles que componen el asunto, así como el aprovechamiento de los recursos ofrecidos por la tecnología, son factores que influyen decisivamente en el resultado final, configurando la actuación del fotógrafo como filtro cultural" (Kossoy, 2000, p. 35).

En cuanto a la materia predominante en esta producción, advertimos un homogéneo perfil de tópicos como el trabajo agrario, la educación escolar, la asistencia médica, los principios de la iglesia católica, que se complementan con el registro del progreso urbano. El perfeccionamiento edilicio de Resistencia aparece en imágenes que capturan el proceso de construcción de seleccionados edificios públicos que representan, además del poder político, dos propuestas de vanguardia: el moderno edificio de la Casa de Gobierno y otro espacio que luego ha tenido un efusivo y vasto uso por el vehemente movimiento cultural resistenciano: el Domo del Centenario, conocido en la actualidad como Zitto Segovia (Imagen 8). En este sentido Raota une dos aspectos que aparecieron separados en los fotógrafos analizados anteriormente: el mundo íntimo del inmigrante (advertido en la 


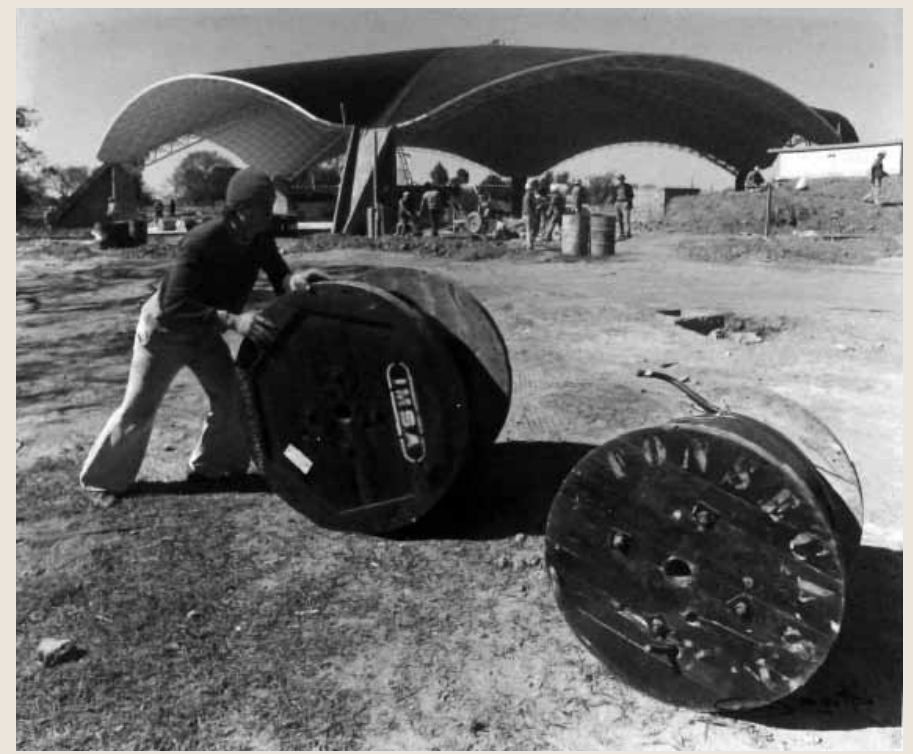

Imagen 8. Pedro Luis Raota Domo del Centenario. Ca. 1978. Col. Banco del Chaco. Museo Provincial de Bellas Artes René Brusau.

producción de Simoni) y las progresistas vistas urbanas del registro arquitectónico realizado por Boschetti. Respecto de este último tipo de tomas, existen unas imágenes muy significativas, realizadas sobre un espacio en el que -en el momento en que Raota lo registra- funciona el Colegio Nacional "José María Paz", pero que para la época de Boschetti había sido una laguna intencionalmente recubierta para la edificación del establecimiento educativo. De esta manera, la fotografía se revela nuevamente como testimonio de la transformación de la ciudad y la emergencia de proyectos modernizadores.

El estilo de estas imágenes es propio de la estética de su autor, identificada por el marcado manejo de luces y sombras. En especial el uso de intensas zonas de luz despuntando desde un fondo sombrío.

Los ambientes elegidos para la mayoría de las tomas resultan los habituales contextos de los personajes y objetos registrados. El rancho del gringo, la escuela de los niños, la tierra del campo arado, la actividad forestal, la naturaleza circundante, el monte y el quebracho, el algodón. Siguiendo es- 
tos escenarios Raota también registra las tradicionales fiestas de inmigrantes del interior chaqueño y sus actividades y costumbres cotidianas: amasar el pan, compartir el mate, asar un lechón, recoger leña, etc. (Imagen 9).

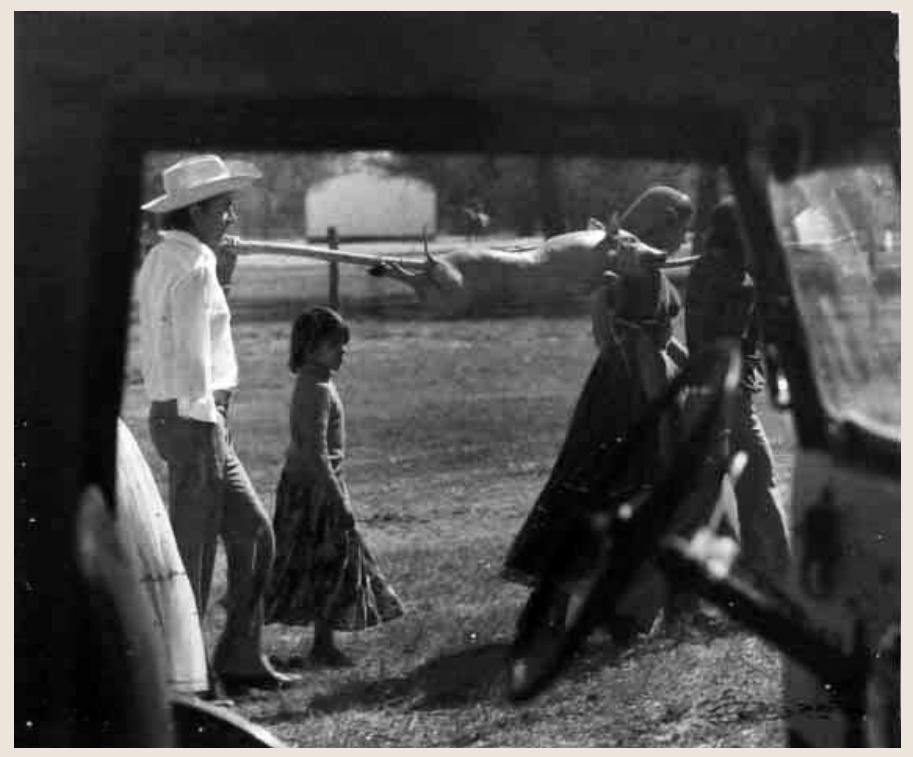

Imagen 9. Pedro Luis Raota Preparando la fiesta. Ca. 1978. Col. Banco del Chaco. Museo Provincial de Bellas Artes René Brusau.

En este sentido Raota centra su interés básicamente en la fotografía social. Sin embargo plantea importantes diferencias respecto de los fotógrafos analizados anteriormente. En particular en el hecho de elegir para sus tomas el rostro del hombre común, en un intento de captar la universalidad de la emoción en el gesto espontáneo: la mirada sabia del anciano, la lágrima y la sonrisa del niño, la pasión del artista, el sacrificio y entereza de la mujer. De este modo la mayoría de estos retratos se encarnan en íconos de belleza que hacen de un retrato particular el retrato universal del niño o la mujer, $e l$ hombre de familia, el trabajador, etc. Confirmando de este modo, la mirada "humanitaria y cosmopolita" que el mismo Raota pretendía plasmar en sus imágenes y que se correspondía con aquellos valores tradicionales que, en definitiva, debían ser sinónimo de los principios de la civilización occidental y cristiana. 


\section{LA FAMILIA, LA CIUDAD Y LA NACIÓN. REFERENTES DE MODERNIDAD}

Retomando las ideas de Rojas Mix (2006, pp. 17-24), un conjunto de imágenes encadenadas en función de un tema o problema determinado conforman un imaginario. Éste es el producto de una agrupación de imágenes que cobra una doble existencia: una abstracta-cognitiva, interiorizada como referente en un individuo o sociedad (imaginario mental) y otra física-material perteneciente a un corpus documental preciso (imaginario icónico-visual).

Al condensar realidades sociales, una imagen da cuenta, en cierto modo, de la manera de ver propia de una época. Y al no existir una mirada "inocente" toda imagen -en nuestro caso fotográfica-, independiente de su calidad, es ideológica o, en otros términos, corresponde a una ideología. Si bien tiene cierto grado de autonomía, está condicionada por los marcos culturales y las formaciones sociales del contexto en el que surge.

En consecuencia, cada uno de los fotógrafos aquí analizados produce imágenes de acuerdo a una ideología, reproduce una visión de mundo de la que los espectadores son más o menos conscientes pero que desinteresadamente la han hecho familiar, transformándola en parte del "sentido común".

Los tres autores aquí analizados confluyen en imágenes que siguen o se corresponden con los paradigmas iconográficos del arte occidental y las convenciones estéticas del momento de cada autor. Las prácticas fotográficas puestas en juego en sus imágenes, respetan los modelos, poses, gestos, actitudes y atributos culturales según los cuales la representación de personas y de lugares -enmarcada en una serie de convenciones- comunica contenidos simbólicos precisos.

A partir de la lectura de las tres colecciones fotográficas chaqueñas del siglo XX que hemos considerado: la perteneciente al pionero y aficionado Simoni, la del amateur devenido reportero urbano Boschetti y la del cosmopolita artista reconocido internacionalmente Raota, es posible concluir que cada una de ellas -a partir de intereses y mediante vías técnicas diferentes- han sido usadas y significadas de diferentes formas, siendo eficientes en la conformación de distintos imaginarios de modernidad: 1) el imaginario familiar-hogareño de los primeros inmigrantes arribados a la entonces colonia Resistencia a finales del siglo XIX, 2) el imaginario urbano-arquitectónico de la incipiente capital chaqueña de Resistencia en las primeras décadas del 1900 y 3) el imaginario nacionalista de la década de 1970. 
Cada uno de estos tres imaginarios está centrado en tres realidades y tres cotidianeidades disímiles de la realidad chaqueña, tres aspectos superficialmente contradictorios, pero esencialmente complementarios entre sí. Aunque ceñido a una particularidad determinada de la vida chaqueña, en un momento específico de su historia, cada imaginario logra trascender dicha parcialidad fáctica y toma como principal referente al hombre chaqueño, su espacio y entorno (material y natural) y su producción (económica y cultural) en el contexto de la modernidad argentina.

Si bien los conjuntos fotográficos son totalmente diferentes entre sí, los tres marcan -en distintos contextos y épocas- un imaginario de progreso chaqueño: el de Simoni, centrado en las razones que llevaron a los inmigrantes a dejar su Europa natal. En tal sentido, las fotografías muestran que el progreso en estas tierras es factible, comunican una necesidad de transmitir las bondades de la nueva realidad, la prosperidad y el porvenir se manifiesta en los modos de vida familiar, en la que los objetos y situaciones cotidianos dan cuenta de su fecunda existencia. Por su parte las imágenes de Boschetti son claramente imágenes del progreso a través de la idea de "ciudad" como su máximo exponente. Este imaginario se vehiculiza a través de un registro de la cultura material sometida a la elección de determinados sectores y edificios, construyendo así una peculiar "estética" del paisaje urbano. Y finalmente las imágenes de Raota, tal vez no en su concepción pero sí en su uso por la institución que las encargó marcan el imaginario nacionalista del Chaco de los setenta. El ideal progresista subyace a la emotividad que produce su poética fotográfica y se vislumbra en valores como el trabajo, la salud, la educación, etc., los que se corresponden con la moral cristiana, la tradición nacional y la "dignidad del ser argentino", que actuaron como componentes del marco ideológico que guió las acciones del llamado "proceso de reorganización nacional".

De este modo los tres imaginarios delimitados en función de la producción de tres fotógrafos diferentes responden meramente a una simplificación de tipo analítico-metodológico. Cada uno se configura como síntesis de realidades mucho más complejas y heterogéneas atravesadas por múltiples matices sociales, políticos, ideológicos y estéticos que aquí apenas se esbozan.

Por otro lado, al ser un espacio ideológico, el imaginario conformado por cada una de estas tres colecciones hace-según determinados criterios de selección- que ciertas imágenes prevalezcan y que otras sean rechazadas. De esta forma se introducen en la memoria de un individuo y/o grupo determinado, generando respectivamente el recuerdo o el olvido de ciertas 
imágenes y la persistencia o la pérdida de los sentidos que éstas comunican. De este modo, al mismo tiempo que las tres colecciones configuran tres modalidades de imaginarios diferentes, las tres pretenden construir y transmitir determinadas memorias.

Concluyendo, es posible afirmar que al momento de registrar el proceso de modernidad por el que atravesaba la sociedad chaqueña durante el periodo comprendido entre los primeros años de su fundación hasta la década del '70, proceso en el que se promovió "el imperio de la razón, se situó al sujeto como conciencia plena de los cursos históricos y se pensó el progreso tecnoindustrial como cultura redentora de la humanidad" (Casullo, 2004, p. 21), la fotografía devino, en términos de Priamo (2000, p. 26), "una herramienta apropiada y natural". Apropiada por su capacidad de testimoniar "fielmente" una realidad que de otra forma no podría ser plasmada ni ilustrada "objetivamente". Natural, en la medida que el medio fotográfico constituyó un artefacto propiamente moderno, acorde al contexto de producción de cada una de estas imágenes. En consecuencia, el medio fotográfico fue tan moderno como moderno aquello que se registraba y pretendía transmitir.

Sin embargo es importante comprender que este uso y sentido de la fotografía no constituyó un hecho aislado, ni una particularidad de la cultura chaqueña, sino que obedeció a una práctica difundida en la mayoría de las nuevas sociedades latinoamericanas. La fotografía resultó, en cada una de estas nuevas sociedades, la carta de presentación al mundo "civilizado y moderno", el portavoz de una idea de país, adelanto y progreso. En este sentido, su función dejaba de ser meramente ilustrativa para pasar a ser un medio de expresión identitaria capaz de manifestar y consolidar una imagen de Nación. Imagen que respondía al deseo de mostrarse y autorreferenciarse según los preceptos de la modernidad.

\section{REFERENCIAS}

Casullo, Nicolás (comp.) (2004). El debate modernidad-posmodernidad. 2a ed., ampliada y actualizada. Buenos Aires: Retórica.

Fernández Pérez, Silvia (2006). "El fin de la dictadura, inicio de disyuntivas: La fotografía en Argentina frente a la recuperación de la vida constitucional". Ojos Crueles No 3. Buenos Aires: Imago Mundis, 47-64.

Kossoy, Boris (2000). Fotografía e historia. Trad. Paula Sirila. Buenos Aires: La Marca.

Miras, Marta (2003). "Sociedad Fotográfica Argentina de Aficionados: La cristalización del cambio", citado en Andrea Cuarterolo, "Imágenes de la Ar- 
gentina opulenta. Una lectura de Nobleza Gaucha (1915) desde el proyecto fotográfico de la Sociedad Fotográfica Argentina de Aficionados". Ojos Crueles No 2. Buenos Aires: Imago Mundi, 59.

Priamo, Luis (2000). "Ernesto H. Schlie y la leyenda de la colonización santafesina". En Vistas de la provincia de Santa Fe 1888-1892. Fotografías de Ernesto Schilie. Santa Fe, Argentina, Diario El Litoral, 11-35.

Rojas Mix, Miguel (2006). El imaginario. Civilización y cultura del siglo XXI. Buenos Aires: Prometeo. 